Check for updates

Cite this: Mater. Chem. Front., 2020, 4, 2472

Received 17th March 2020,

Accepted 10th June 2020

DOI: 10.1039/d0qm00159g

rsc.li/frontiers-materials

\title{
3D printed composites from heat extruded polycaprolactone/sodium alginate filaments and their heavy metal adsorption properties $\dagger$
}

\author{
Ioannis L. Liakos, (D) * Alessio Mondini, (D) Emanuela Del Dottore, (DD \\ Carlo Filippeschi, Francesca Pignatelli (D) and Barbara Mazzolai*
}

\begin{abstract}
Removal of heavy metals can be achieved through the adsorption of metal ions onto the surfaces of various materials and composites that either have such properties naturally or are modified to obtain those capabilities. Sodium alginate (SA), a marine polysaccharide, is well known for its heavy metal adsorption ability. In this work, we combined polycaprolactone (PCL), a bio-based thermoplastic polymer, with SA with the use of a solvent and the resulting films were inserted into a heat extruder to create PCL/SA filaments. Such PCL/SA filaments were preferred compared to films, since they have greater stability in water and can be used in additive manufacturing technology. Hydrogen bonds are supposed to be formed between the hydroxyl groups of SA and the carbonyl groups of PCL. The resulting composite filaments with SA were able to adsorb heavy metals such as copper ions in water, which was used as a model, with maximum adsorption capacity around $90 \mathrm{mg} \mathrm{g}^{-1}$. Such innovative filaments were used with 3D printing technology to additively manufacture composite structures able to remediate environments contaminated with heavy metals. The filaments were tested with a commercial 3D pen, a 3D printer capable of fused deposition modelling and a plant-inspired self-growing robot. The resulting printed structures were able to adsorb copper ions as the free-standing filaments did.
\end{abstract}

\section{Introduction}

Various geogenic natural events (weathering and volcanic eruptions) and industrialisation (mining, industrial operations, and domestic and technological applications) have led to pollution of water, soil and air with heavy metals such as $\mathrm{Cr}, \mathrm{Cu}, \mathrm{Ni}, \mathrm{As}, \mathrm{Cd}, \mathrm{Hg}, \mathrm{Pb}, \mathrm{Zn}, \mathrm{Co}$, $\mathrm{Fe}, \mathrm{Mg}, \mathrm{Mn}$ and others. ${ }^{1}$ Urban cities with industry and/or ports in their vicinity have elevated levels of heavy metals such as $\mathrm{Cr}, \mathrm{Fe}, \mathrm{Cu}$, $\mathrm{Zn}, \mathrm{Cd}, \mathrm{Pb}$ and $\mathrm{Al}$ in their atmosphere. ${ }^{2}$ In 2007, the World Health Organization's report on heavy metals in air pollution has shown that heavy metals such as lead, cadmium and mercury are common air or water pollutants in industrialised areas that pose many health problems such as lung cancer, and developmental and neurobehavioral effects. ${ }^{3-5}$ Heavy metals can enter the food chain (fish, vegetables etc.) and pass into humans. Elevated values of such elements in the human body can provoke many diseases such as cancer, kidney toxicity, nervous system damage, autoimmune disorders and others. ${ }^{1,6,7}$ Therefore it is very important to create methodologies and materials that adsorb

Center for Micro-BioRobotics, Istituto Italiano di Tecnologia (IIT), Viale Rinaldo Piaggio 34, Pontedera (Pisa) 56025, Italy. E-mail: ioannis.liakos@iit.it, barbara.mazzolai@iit.it

$\dagger$ Electronic supplementary information (ESI) available. See DOI: 10.1039/ d0qm00159g heavy metals and remediate ecosystems such as sea, lake or river water and the soil. The most common current systems for heavy metal remediation include chemical precipitation, ion exchange, adsorption with new adsorbents, membrane filtration, bioremediation, phytoremediation, electrodialysis and photocatalysis. ${ }^{6,8,9}$ Each of these methods has advantages and disadvantages. For example, chemical precipitation, even though it is the most widely used method for heavy metal removal from inorganic effluent, requires large amounts of chemicals to reduce metals to an acceptable level of discharge. Ion exchange usually involves a solid capable of exchanging either cations or anions from the surrounding materials. The drawbacks of ion exchange are that is not selective and cannot handle concentrated metal solutions as the matrix gets easily saturated by organics and other solids in the wastewater. The adsorption method is currently receiving more attention since it is relatively low cost, the materials used can be recycled, it removes a high amount of heavy metals and it is easy to operate. ${ }^{6,10}$

Nature has shown us that many plants and macroalgae (seaweeds) are able to adsorb and/or absorb heavy metals. For example, a recent study ${ }^{11}$ showed that heavy metals were accumulated in roadside plant species of Athyrium esculentum, Chromolaena odorata and Lantana camara. $\mathrm{Fe}, \mathrm{Cd}, \mathrm{Cu}$ and $\mathrm{Pb}$ were found to accumulate in the plant species with concentrations varying from $0.12 \mathrm{mg} \mathrm{kg}^{-1}$ for Cd to $850 \mathrm{mg} \mathrm{kg}^{-1}$ for Fe. The results also showed that all parts of the plant could accumulate 
heavy metals and that the absorption of the three plants had the rank: root $>$ stem $>$ leaves. Wild berries and edible mushrooms were also able to absorb heavy metals in an area affected by smelter emissions. $^{12} \mathrm{Ni}$ and $\mathrm{Cu}$ were detected in the wild berries and mushrooms near the smelter complex at elevated levels compared to background levels. Seaweeds or macroalgae have also been found to absorb heavy metals. A recent study ${ }^{13}$ showed that ten metals and metalloids were present in 295 dried seaweeds (brown and red). The elements accumulated in seaweeds were decreasing as: $\mathrm{Al}>\mathrm{Mn}>\mathrm{As}>\mathrm{Cu}>\mathrm{Cr}>$ $\mathrm{Ni}>\mathrm{Cd}>\mathrm{Se}>\mathrm{Pb}>\mathrm{Hg}$. In another study, ${ }^{14}$ the green seaweed Ulva lactuca and the red seaweed Agardhiella subulata were concurrently exposed to five metals, $\mathrm{Cu}, \mathrm{Ni}, \mathrm{Pb}, \mathrm{Cd}$ and $\mathrm{Zn}$. It was found that the distribution of metals in both seaweed species changed with increasing metal exposure concentrations, resulting in higher $\mathrm{Cu}$ and $\mathrm{Zn}$ proportions in the metal exposed groups compared to the respective controls. Moreover, Ulva lactuca accumulated higher concentrations of metals when exposed to each metal individually rather than in metal mixtures, suggesting interactions among metals for uptake and/or bioaccumulation.

There is a lot of research in creating novel composite materials to remediate heavy metal pollution by ion-exchange and adsorption processes. Many materials exist that are able to adsorb heavy metals and they are usually derived from agricultural waste, industrial byproducts, natural materials and biopolymers. Examples of adsorbents include modified natural materials (zeolites, clays, and zirconium phosphate); industrial by-products (graphene and titanium oxide); agricultural and biological waste (hazelnut shell, rice husk, pecan shells, jackfruit, maize cob, algae, and bacterial biomass); and biopolymers and hydrogels (chitosan, chitin, starch, alginate, polysaccharides, and sugars). ${ }^{6,15,16}$ Such adsorbents usually have to be inserted into a matrix so the adsorption process is more practical and efficient. Therefore composites of such adsorbents with other polymers are necessary for the best design and feasibility of the remediation process. For example, graphene oxide has been used with chitosan, alginate and silica to create composites for heavy metal adsorption. ${ }^{17}$ A silica activated carbon composite has been proved efficient for removing heavy metals. ${ }^{18}$ Porous magnetic composites of cobalt ferrite/silica were prepared and were able to remove heavy metals. ${ }^{19}$ Sodium alginate (SA) has been used extensively in heavy metal adsorption due to its properties to adsorb metal ions. Usually SA, since it is water soluble, is crosslinked with calcium chloride to create beads with other additives that can enhance/ modify the metal ion adsorption capacities, but also keep the alginate stable in water. For example calcium alginate has been used with other additives such as zeolites or iron modified zeolites to create beads that were able to adsorb heavy metals. ${ }^{20}$ Calcium alginate has also been used with graphene oxide to adsorb Mn(II) from water solutions with removal efficiency around 55\% and an

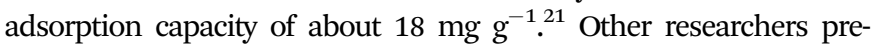
pared boric acid and calcium chloride cross-linked polyvinyl alcohol/alginate beads with fungal conidia biomass to effectively remove $\mathrm{Cu}, \mathrm{Pb}$ and $\mathrm{Cd}^{22}$ The accumulation of heavy metals in calcium alginate gels is usually a combination of ionexchange and chemical coordination. Calcium alginate linked with EDTA was found to remove more than $85 \%$ of $\mathrm{Cd}, \mathrm{Pb}, \mathrm{Cu}$, $\mathrm{Cr}$, and $\mathrm{Co}^{23}$ Calcium alginate beads were also able to separately absorb $\mathrm{Cu}, \mathrm{Zn}$, Ni and $\mathrm{Cd}$ but show selective absorption toward $\mathrm{Cu}$ when all the metals were mixed in the solution. ${ }^{24}$

There is no any current technology that uses thermoplastic filaments with SA to adsorb heavy metals. The scope of this research is to create novel composite filaments based on thermoplastic polymers such as PCL that are water stable and compatible with 3D printing techniques for applications in the field of environmental remediation of heavy metals. The proposed PCL/SA filaments have the mechanical strength and durability to be used in many applications ranging from environmental to biomedical. This work is trying to mimic plants and macroalgae for their heavy metal accumulation, and use the developed filaments by additive manufacturing ${ }^{25}$ for self-growing robots that can autonomously and safely navigate a contaminated area. The use of a biocompatible and biodegradable polymer (PCL) and a polysaccharide (SA) that exists in macroalgae as alginic acid mimics the heavy metal accumulation of macroalgae. Bioaccumulation in macroalgae, also termed active biosorption, involves two processes: a fast process of biosorption of toxic elements on the surface and a slower process of bioaccumulation by transportation of metal ions into cells found in algae. ${ }^{26}$ Adsorption, chelation/complexation, ion exchange and surface precipitation are different processes involved in biosorption. Ion exchange is considered the principle mechanism in biosorption and occurs through different functional groups present on the surface of plants and algae. ${ }^{26,27}$ For example, in algae the functional groups that will react with heavy metals are alginate and sulfonated polysaccharides. Monovalent ions present in alginate or other biomass, such as $\mathrm{Na}^{+}$ or $\mathrm{H}^{+}$, have been reported to be involved in the ion exchange process due to a weak attachment to biomass compared to divalent ions present in heavy metals. $^{26,27}$ The mechanism of heavy metal accumulation from terrestrial or soil plant species is more complex, involving many steps, but includes also the accumulation of heavy metals using chelating agents released from the plants. ${ }^{28}$ Usually the accumulation of heavy metals by sodium or calcium alginate involves both ion-exchange and chemical coordination methods, since heavy metals are able to replace sodium or calcium ions and also bind to specific chemical groups such as $\mathrm{COOH}$ and/or $\mathrm{OH}$ groups found in alginate molecules. ${ }^{10} \mathrm{Here}$, in the present article, the copper adsorption/accumulation from PCL/SA filaments and biomimetic 3D-printed plant inspired structures is discussed. The $3 \mathrm{D}$ printers used to create the 3D structures were: a 3D pen, ${ }^{29}$ a classic Fused Deposition Modelling (FDM) 3D printer ${ }^{30}$ and a plantinspired self-growing robot with embedded FDM technology. ${ }^{25}$ Adsorption of copper ions from copper sulphate deionised water solutions was used as a model, since it was comparatively easy to operate, but similar adsorption of metal ions can happen in air as well, particularly under moist conditions.

\section{Experimental}

\subsection{Materials}

Polycaprolactone (PCL) was received as a courtesy from Perstorp through Reschemitalia, with product code CAPA 6800. 
Dichloromethane (DCM), sodium alginate (SA) medium viscosity and copper sulphate pentahydrate $\left(\mathrm{Cu}_{2} \mathrm{SO}_{4} \cdot 5 \mathrm{H}_{2} \mathrm{O}\right)$ were purchased from Sigma Aldrich. The heat extruder was purchased from Filabot (Filabot EX2). Deionised water was obtained from an Elix Technology Inside Advantage 10 water purification system.

\subsection{Preparation of filaments}

To create the composites, solutions of $8.42 \% \mathrm{w} / \mathrm{w}$ of PCL (CAPA $6800)$ in DCM were used. Then SA (medium viscosity) was added into the above solutions at $5,10,15,20,25$ or $30 \% \mathrm{w} / \mathrm{w}$ with respect to PCL. The PCL/SA solutions were left under mixing with a magnetic stirrer at $600 \mathrm{rpm}$ for $6 \mathrm{~h}$ to ensure complete dissolution of the PCL and homogeneous dispersion of the alginate with the polymer solution (Fig. 1a). Then the solutions were cast into glass Petri dishes and left under a fume hood overnight to ensure complete evaporation of the DCM. The resulting films were quite homogeneous and were then cut into small pieces (Fig. 1b). Then they were inserted into a heat extruder at $90{ }^{\circ} \mathrm{C}$ to create PCL/SA filaments (Fig. 1c) with improved homogeneity compared to the films.

\subsection{Preparation of 3D structures}

A 3D pen model Sunlu (SL-300A) operated at $60-70{ }^{\circ} \mathrm{C}$ was used to create $3 \mathrm{D}$ pen printed structures. For the $3 \mathrm{D}$ fused deposition modelling (FDM) a Creality CR-10 model was used. The printing parameters for PCL/5 and $15 \%$ SA were $185^{\circ} \mathrm{C}$ and $45{ }^{\circ} \mathrm{C}$ nozzle and bed temperatures, respectively, whereas the printing and bed temperatures for $\mathrm{PCL} / 30 \% \mathrm{SA}$ were $210{ }^{\circ} \mathrm{C}$ and $45{ }^{\circ} \mathrm{C}$, respectively. The speed of the 3D printing was $20 \mathrm{~mm} \mathrm{~min}^{-1}$ for all the studied SA concentrations. Solidworks software was used to create the 3D structure, which was a tube with an internal and external diameter of 2 and $2.2 \mathrm{~cm}$, respectively. The height of the tube was $2.5 \mathrm{~cm}$. Cura software was used to build the 3D design file. Then the design file was transferred to Creality CR-10 for printing. The growing $\operatorname{robot}^{25}$ used to self-deploy 3D biomimetic structures embeds a miniature 3D printer-like mechanism at its tip, with an overall $50 \mathrm{~mm}$ diameter. It includes a gear-based feeder mechanism to pull the filament, a heater that melts the filament and extrudes it, and a plotting unit to circularly deposit the filament and realize a plant-like tubular body. The feeding speed, extrusion temperature and plotting speed have been properly tuned for the correct deposition of the PCL/SA composite. In particular, the deposition process has been obtained with an extrusion temperature of $135{ }^{\circ} \mathrm{C}$ and a plotting and feeding speed of $12.3 \mathrm{~mm} \mathrm{~s}^{-1}$, which results in an overall growing speed of the tubular structure of $6 \mathrm{~mm} \mathrm{~min}^{-1}$.

\subsection{Optical and scanning electron microscopy (SEM) and electron diffraction X-ray (EDX) spectroscopy}

A Hirox digital microscope $\mathrm{KH}-8700$ was used to collect optical microscopy 3D images of the 3D structures (XIROX: Tokyo, Japan).
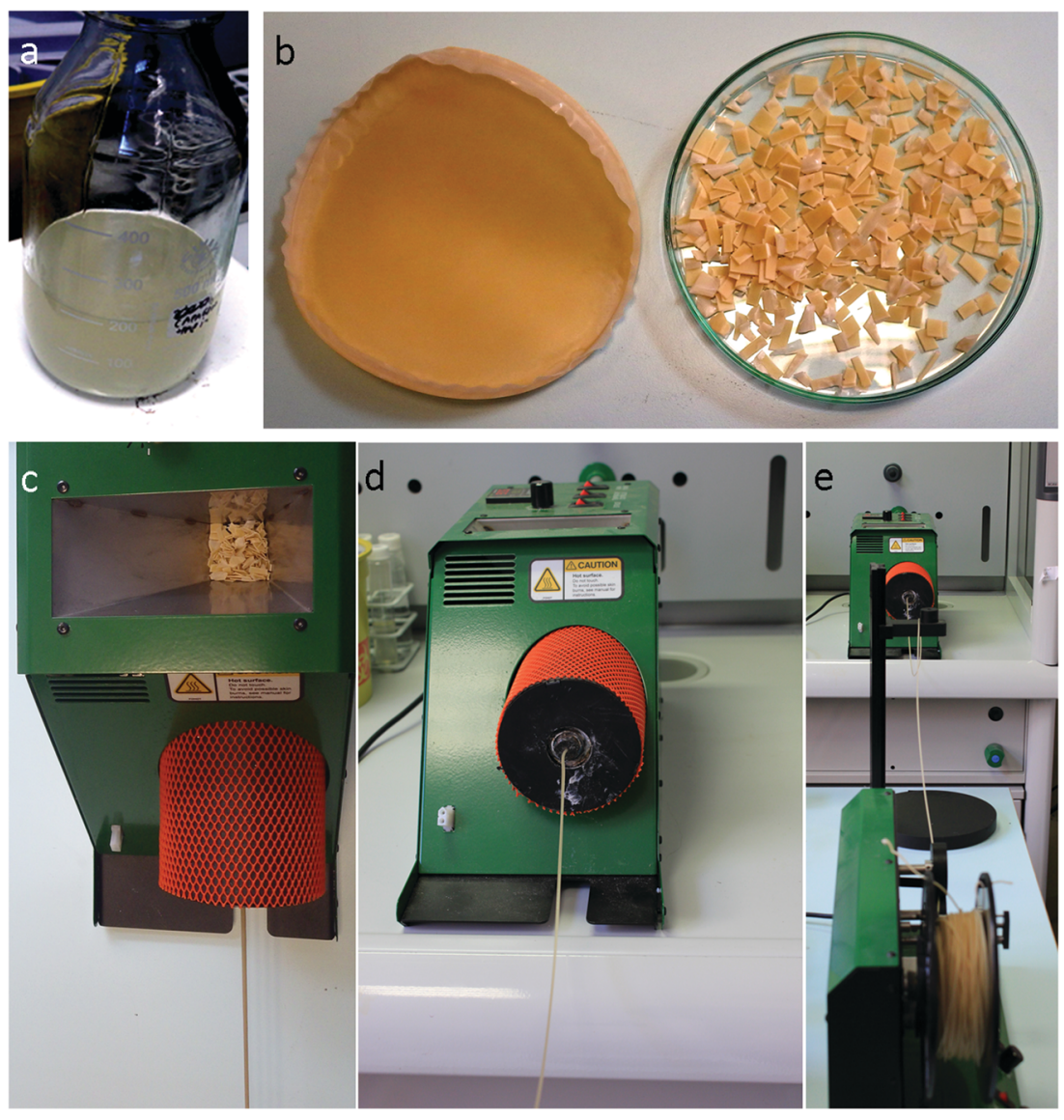

Fig. 1 (a) PCL and SA in DCM; (b) cast and cut film and (c)-(e) extrusion method to create filaments of PCL/SA. 
An FEI Helios NanoLab Dual Beam microscope (FEI Company: Hillsboro, OR, USA) equipped with a Bruker Quantax 200 EDX spectroscope (Bruker Nano GmbH: Berlin Germany) was used to obtain SEM images and EDX spectra. In conjunction with the SEMEDX hardware, FEI image analysis software and Esprit EDX software provided imaging and graphical spectra results. The SEM was operated under a high vacuum at $5 \mathrm{kV}$ and $45 \mathrm{pA}$ for imaging and at $10 \mathrm{kV}$ and $0.17 \mathrm{nA}$ for EDX spectra acquisition. The working distance was approximately $4.5 \mathrm{~mm}$.

\subsection{Dynamic scanning calorimetry (DSC)}

The thermograms were recorded on a Mettler Toledo DSC1 Star System instrument. For each measurement, $\sim 10 \mathrm{mg}$ of material was put in a standard aluminium sealed capsule. After an isotherm at $10{ }^{\circ} \mathrm{C}$ for $2 \mathrm{~min}$, a temperature scan was performed from $10{ }^{\circ} \mathrm{C}$ to $100{ }^{\circ} \mathrm{C}$ with a rate of $10{ }^{\circ} \mathrm{C} \mathrm{min}^{-1}$. For each alginate concentration the measurement was repeated on three different samples so as to calculate the average melting temperature and average crystallinity of the composite together with the standard deviations.

\subsection{Mechanical properties}

A Zwick Roell Model Z005 instrument was used to measure the Young's modulus. The pre-load was set at $0.1 \mathrm{MPa}$ and the speed of pre-load was set at $5 \mathrm{~mm} \mathrm{~min}^{-1}$.

\subsection{Ultraviolet (UV)-visible spectroscopy}

UV-vis absorption spectra were recorded on a PerkinElmer spectrophotometer LAMBDA 45. For the investigation of the adsorption kinetics, filaments weighing $100 \mathrm{mg}$ were immersed in $6 \mathrm{~mL} 0.17$ and $1 \% \mathrm{w} / \mathrm{w} \mathrm{Cu}_{2} \mathrm{SO}_{4}$ aqueous solutions. The UV-vis absorbance at different time intervals was recorded. In parallel two control samples with only PCL (without SA) in 0.17 or $1 \% \mathrm{w} /$ ${ }_{\mathrm{W}} \mathrm{Cu}_{2} \mathrm{SO}_{4}$ aqueous solutions were measured at different times in order to check the stability of the solutions and compare those data with the filaments with SA. For the UV experiments of the films shown in the supporting information $50 \mathrm{mg}$ of the films were immersed in $3 \mathrm{~mL}$ of 0.17 and $1 \% \mathrm{w} / \mathrm{w} \mathrm{Cu}_{2} \mathrm{SO}_{4}$ aqueous solutions.

\section{Results and discussion}

\subsection{PCL/SA films and filaments; stability studies}

Before creating the filaments, the formed PCL/SA films were tested for their water stability and/or their copper adsorption capabilities. It was found that the films were able to adsorb copper ions, due to the presence of SA, but their adsorption was not uniform and more importantly sodium alginate was detached from the PCL polymer within a few hours as seen in Fig. S1 (ESI $\dagger$ ). For the $1 \% \mathrm{w} / \mathrm{w} \mathrm{Cu}_{2} \mathrm{SO}_{4}$ solution SA was crosslinked and stayed on the PCL matrix due to the high crosslinking effect of the copper sulphate at this concentration (similarly to $1.4 \%$ maximum cross-linking of calcium chloride), ${ }^{31,32}$ but for the $0.17 \% \mathrm{w} / \mathrm{w} \mathrm{Cu}_{2} \mathrm{SO}_{4}$ solution (where the SA cross-linking is low) and/or simple water SA detached
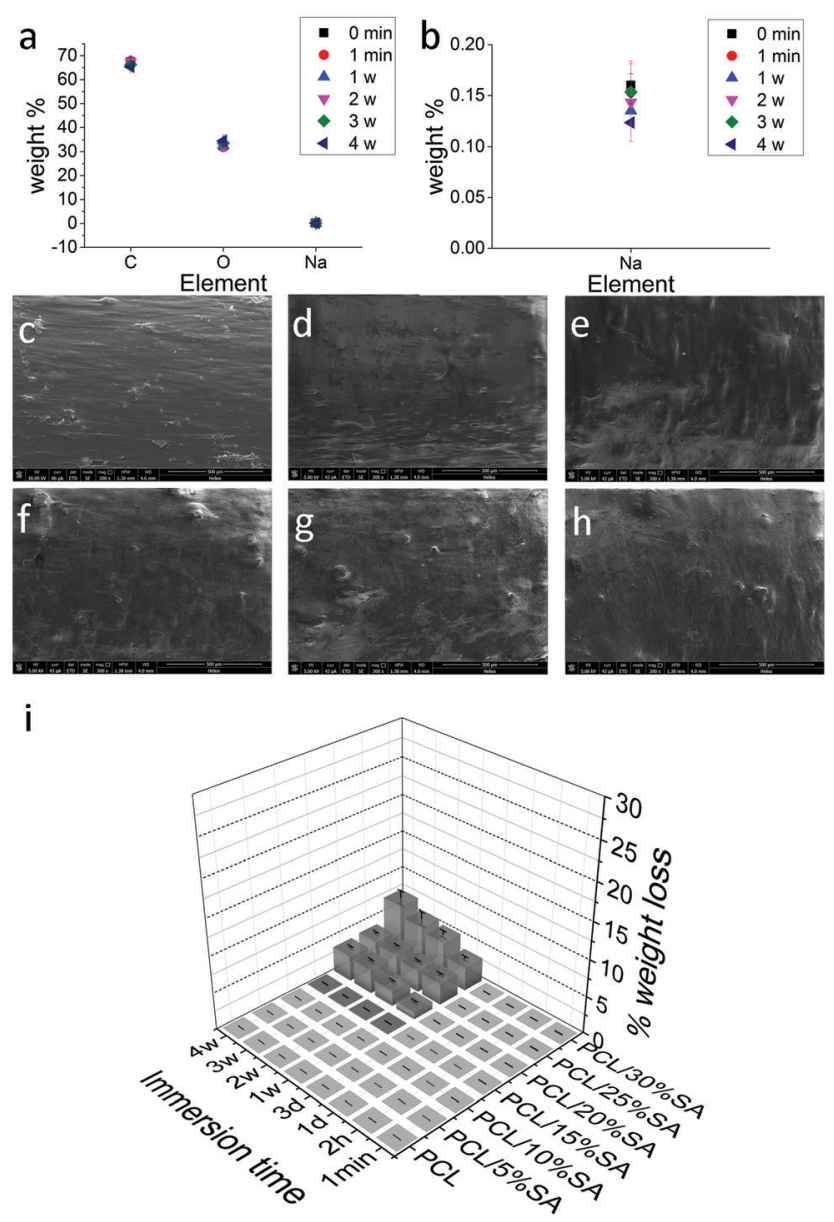

Fig. $2 \mathrm{PCL} / 15 \% \mathrm{SA}$ filament at time intervals in water (a) and (b) EDX analysis of $\mathrm{C}, \mathrm{O}$ and $\mathrm{Na}$ elemental weight\% concentration; SEM images (500 $\mu \mathrm{m}$ scale bar) (c) -(h) 0 min, 1 min, $1 \mathrm{w}, 2 \mathrm{w}, 3 \mathrm{w}$ and $4 \mathrm{w}$, respectively; and (i) \% weight loss versus time of $\mathrm{PCL} / 5-30 \% \mathrm{SA}$ in deionised water.

from the PCL matrix within a few hours. For this reason, the filaments produced from the heat extrusion process were also tested for their water stability. The resulting filaments to be useful as novel composites for heavy metal adsorption need to be stable in aquatic or humid conditions for water and soil heavy metal remediation respectively. Electron diffraction X-ray (EDX) analysis of PCL/15\%SA filaments showed that they do not release SA since the concentration of $\mathrm{C}, \mathrm{O}$ and $\mathrm{Na}$ remained almost stable within a month of the filament being in deionised water (Fig. 2a and b). The weight difference before and after water immersion of $100 \mathrm{mg}$ PCL/SA filaments in $6 \mathrm{~mL}$ of deionised water showed that the PCL/SA filaments up to $15 \%$ SA were stable in deionised water up to the tested time (1 month) and no considerable loss of SA was detected. In Fig. $2 \mathrm{c}-\mathrm{h}$ the SEM images of the PCL/15\%SA filaments immersed in deionised water are shown; there the filaments are becoming slightly smoother due to the little swelling of SA. Similar studies were done for the PCL/5-30\%SA filaments and after 3 days some SA detached from the PCL/20-30\%SA composite filaments as shown in Fig. 2i, since in deionised water there are no ions to attach to SA and after a prolonged time deionised water can 
dissolve some of the ions present in sodium alginate $\left(\mathrm{Na}^{+}\right.$and $\mathrm{COO}^{-}$). Nevertheless such PCL/SA filaments were extremely stable in air and some little change in their weight could be due to the adsorption or desorption of humidity from the air.

\subsection{Dynamic scanning calorimetry (DSC) analysis and mechanical properties}

DSC experiments on PCL and PCL/SA filaments were done to calculate their melting points and \% crystallisation. As shown in Fig. 3a, the crystallisation of PCL consistently decreases with increasing the SA concentration, whereas the melting point of PCL/SA increases by $2{ }^{\circ} \mathrm{C}$ with respect to the bare PCL filament, independently of the SA concentration. These results revealed bonding between PCL and SA, such as hydrogen bonds. Such hydrogen bonds are formed between the hydroxyl group of SA and the carbonyl groups of PCL. A hydrogen bond mechanism was also proposed by other researchers of another polysaccharide (starch) with PCL, ${ }^{33}$ where it was proposed that such hydrogen bonds inhibit the movement of PCL chains for crystallisation. Additionally, the incorporation of SA into PCL showed that the Young's modulus of the filaments is increasing consistently as the percentage of SA in PCL increases (Fig. 3b). Usually hydrogen bonds in polymers and hydrogels improve the mechanical properties and strength of the composite materials. ${ }^{34,35}$ The hydrogen bonds between the $\mathrm{OH}$ groups of alginate and the carbonyl groups of PCL are illustrated in Fig. 3c, which is the reason for the stability of SA in the PCL matrix.

\subsection{Scanning electron microscopy (SEM) and electron diffraction X-ray (EDX) spectroscopy}

Up to now, we have shown the formation of PCL/SA composites and the hydrogen bonds that were created between the two polymers making the composite filaments stable in water. The next step was to test the heavy metal adsorption properties of those composites. The PCL/SA filaments were tested for their $\mathrm{Cu}$ adsorption by immersing these filaments in $\mathrm{Cu}_{2} \mathrm{SO}_{4}$ water solutions. SEM was used to study the topography of the filaments with and without alginate before and after their $4 \mathrm{~h}$ immersion in $(1 \% \mathrm{w} / \mathrm{w}) \mathrm{Cu}_{2} \mathrm{SO}_{4}$ water solution. The results are shown in Fig. 4. It is clearly seen that all the filaments with alginate can absorb $\mathrm{Cu}$ ions (Fig. 4a2-f2), where the heavy metals are shown as fibrous structures on top of the PCL/SA filament surface. Moreover, all the PCL/SA filaments are found to be homogeneous without any separation of phases, which shows once again the attraction of alginate to the PCL molecules (Fig. 4a-f1). EDX spectroscopy was employed to detect the elements on the surfaces of the filaments. Carbon and oxygen arise from both PCL and SA (Fig. 4g), whereas Na arises only from SA (Fig. 4h). Additionally all the PCL/SA filaments had Cu (1-4 wt\%) and $\mathrm{S}(0.2-1.2 \mathrm{wt} \%)$ elements on their surface (Fig. 4h). The trend in the concentration of the $\mathrm{Cu}$ ions on increasing the SA concentration in the filaments was not possible to determine since $\mathrm{Cu}_{2} \mathrm{SO}_{4}$ was adsorbed as a fibrous non-uniform structure on top of the composite filament and EDX analysis calculates a larger area on the composite surface, making the quantitative comparison between different SA concentrations difficult as seen from Fig. $4 \mathrm{~h}$.

\subsection{Ultraviolet (UV) absorption spectroscopy}

To accurately study the adsorption kinetics of $\mathrm{Cu}$ ion adsorption, UV spectroscopy was employed. 0.17 and $1 \% \mathrm{w} / \mathrm{w} \mathrm{Cu}_{2} \mathrm{SO}_{4}$ water solutions were used and their UV absorption was taken between 500 and $1000 \mathrm{~nm}$. These solutions showed an absorption band in this region with the highest peak at $810 \mathrm{~nm}$.
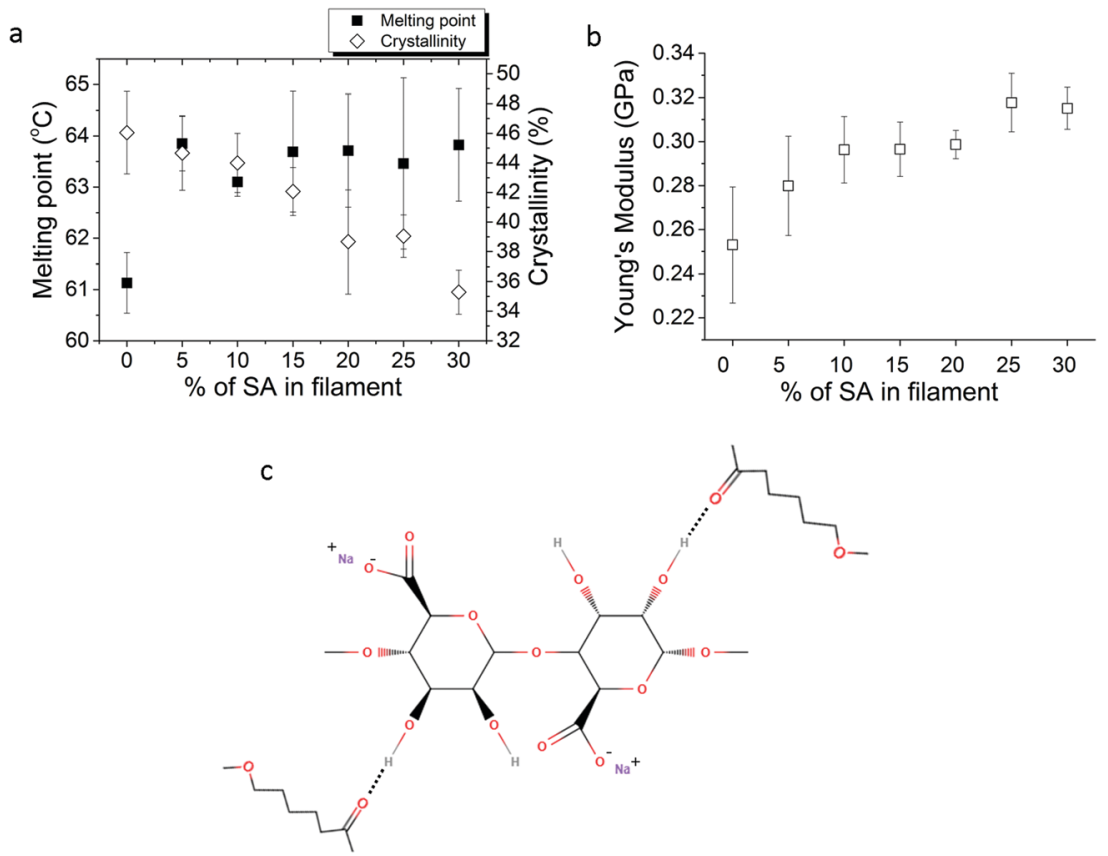

Fig. 3 (a) Melting point and \% crystallinity and (b) Young's modulus of PCL and PCL/SA filaments and (c) illustration of H-bonding between SA and PCL. 


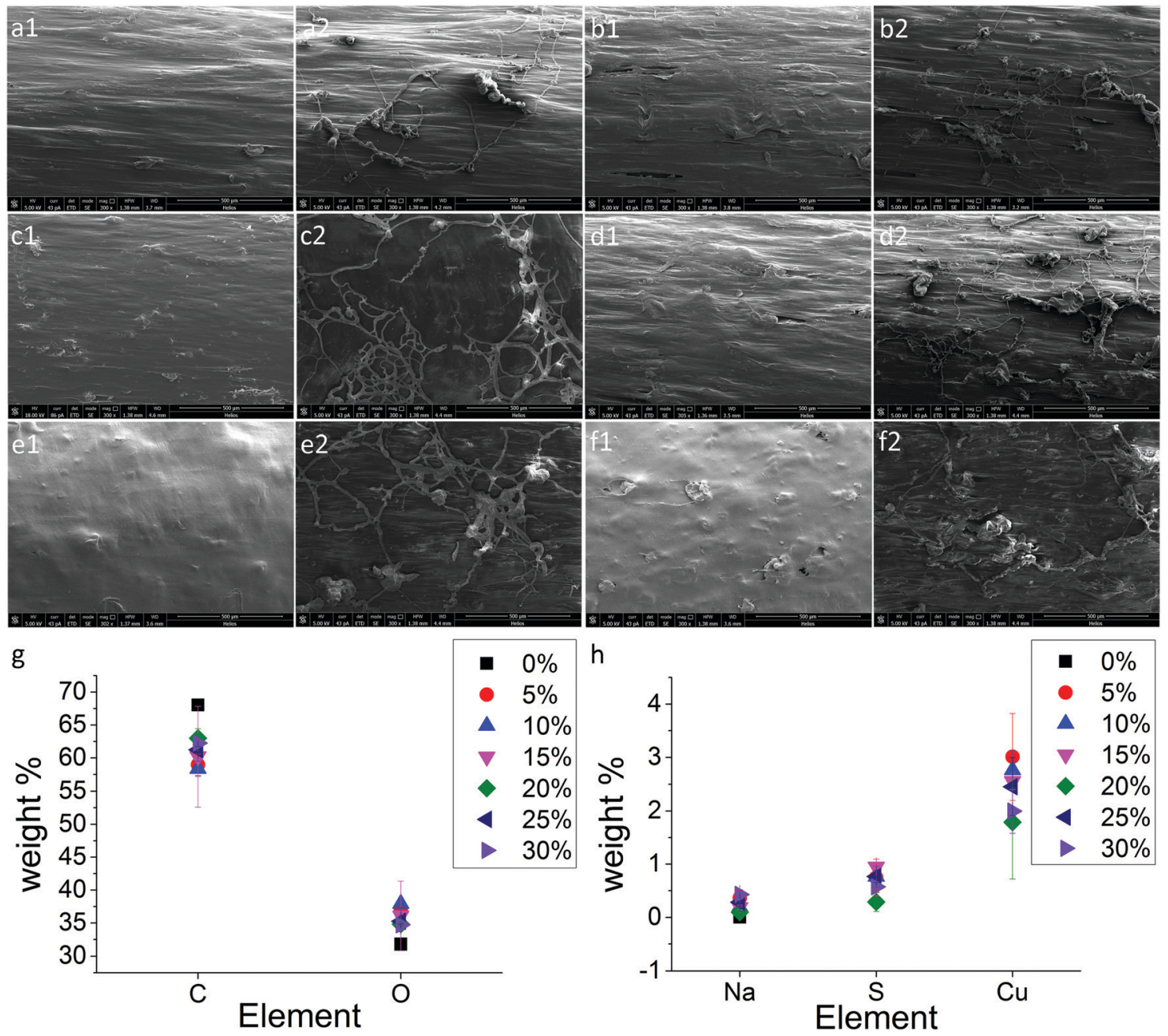

Fig. 4 SEM of (a) PCL/5\%SA, (b) PCL/10\%SA, (c) PCL/15\%SA, (d) PCL/20\%SA, (e) PCL/25\%SA, and (f) PCL/30\%SA where 1 denotes before Cu adsorption and 2 denotes after 4 hours of $\mathrm{Cu}$ adsorption; and (g) and (h) EDX elemental analysis of PCL and PCL/5-30\%SA filaments.

A PCL/ 5 or 15 or $30 \%$ SA filament was inserted in a 0.17 and $1 \%$ $\mathrm{w} / \mathrm{w} \mathrm{Cu}_{2} \mathrm{SO}_{4}$ water solution and at regular time intervals the spectra of the solutions were measured. The results of the $\%$ concentration change of $\mathrm{Cu}$ ions are shown in Fig. 5a and $\mathrm{b}$. PCL was not able to adsorb any $\mathrm{Cu}$ ions. From the other side, all the filaments with SA showed some $\mathrm{Cu}$ adsorption. The adsorption of $\mathrm{Cu}$ ions from the filaments was SA concentration dependent. The higher the SA concentration in the filament the higher was its $\mathrm{Cu}$ adsorption. PCL/30\%SA had the highest $\mathrm{Cu}$ adsorption among the filaments, and its process was continuous even after one month of immersion, whereas PCL/5 and $15 \%$ SA reached saturation. The copper reduction after 3 days of filament immersion in the $0.17 \% \mathrm{w} / \mathrm{w} \mathrm{Cu}_{2} \mathrm{SO}_{4}$ water solution was approximately $11.7,17$ and $38.4 \%$ for PCL/5\%SA, PCL/15\%SA and PCL/30\%SA respectively, as demonstrated in Fig. 5a1. Similarly, the copper reduction after 3 days of filament immersion in the $1 \% \mathrm{w} / \mathrm{w} \mathrm{Cu}_{2} \mathrm{SO}_{4}$ water solution was approximately 2.2, 3.0 and 3.9\% for PCL/5\%SA, PCL/15\%SA and PCL/ $30 \%$ SA respectively, as demonstrated in Fig. 5b1. The copper reduction after 30 days of filament immersion in the $0.17 \% \mathrm{w} / \mathrm{W}$
$\mathrm{Cu}_{2} \mathrm{SO}_{4}$ water solution was approximately 11.1, 20.8 and $91.5 \%$ for $\mathrm{PCL} / 5 \% \mathrm{SA}, \mathrm{PCL} / 15 \% \mathrm{SA}$ and $\mathrm{PCL} / 30 \% \mathrm{SA}$ respectively, as demonstrated in Fig. 5a1. Similarly, the copper reduction after 30 days of filament immersion in the $1 \% \mathrm{w} / \mathrm{w} \mathrm{Cu}_{2} \mathrm{SO}_{4}$ water solution was approximately 2.9, 5.0 and $14.7 \%$ for PCL/5\%SA, $\mathrm{PCL} / 15 \% \mathrm{SA}$ and $\mathrm{PCL} / 30 \% \mathrm{SA}$ respectively, as demonstrated in Fig. $5 \mathrm{~b} 1$.

Moreover, we were able to fabricate 3D structures by adopting the developed PCL/15\%SA filament with FDM. Fig. 6a1-a3 show the progress and realization of plant-like (Fig. 6a2) and macroalgae-like structures (Fig. 6a3) obtained with a commercial 3D pen. Fig. 6b1-b3 show the 3D printing of a tubular design obtained using the commercial FDM 3D printer Creality CR-10. A root-like tubular structure was also obtained by using the growing robot (Fig. 6c1-c3). Plant roots and sea macroalgae were envisaged as models since both of them are known for their heavy metal adsorption properties. All 3D structures and approaches were shown to have layer-by-layer formation, varying in the diameter of each layer depending on the 3D printing techniques used. SEM and optical microscopy data on the PCL/ 
a1

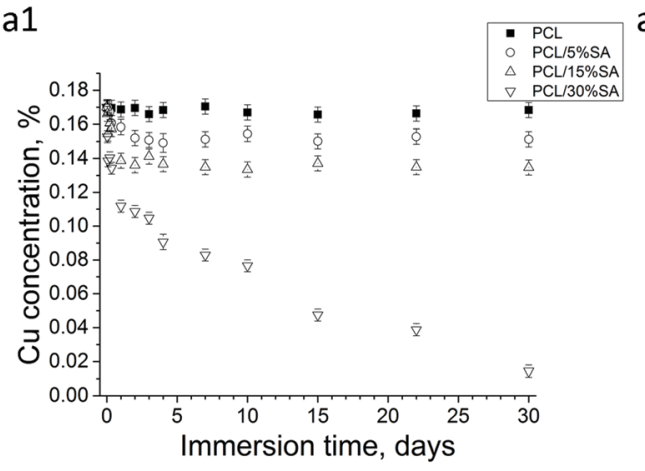

a2

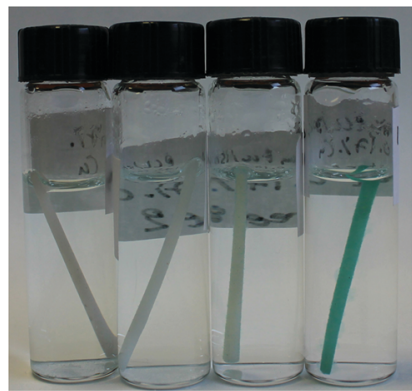

b1

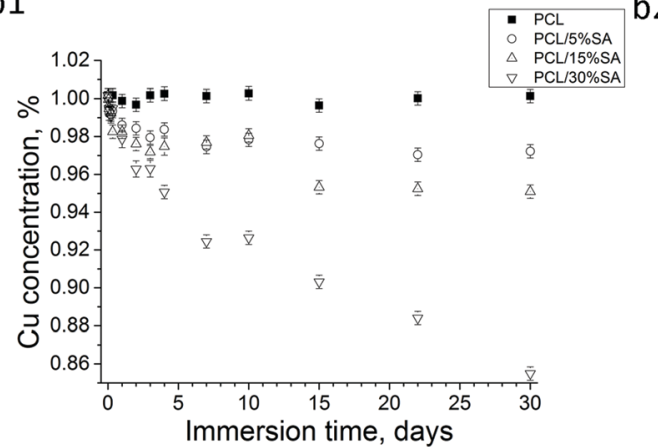

b2

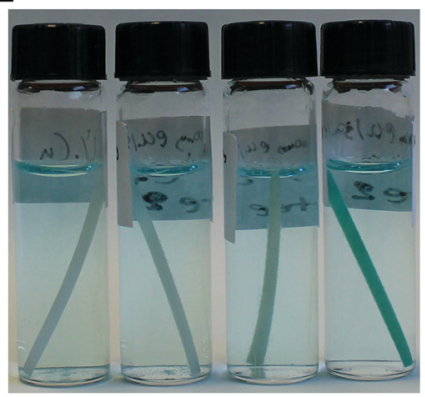

Fig. $5 \%$ concentration of Cu vs. immersion time of the PCL/5-30\%SA filament in $6 \mathrm{~mL}$ of (a1) $0.17 \%$ and (b1) $1 \%$ w/w Cu $2 \mathrm{SO}_{4}$ solution. Photographs of the $\mathrm{PCL}, \mathrm{PCL} / 5 \% \mathrm{SA}, \mathrm{PCL} / 15 \% \mathrm{SA}$ and $\mathrm{PCL} / 30 \% \mathrm{SA}$ filaments (from left to right) in the (a2) $0.17 \%$ and (b2) $1 \% \mathrm{w} / \mathrm{w} \mathrm{Cu}_{2} \mathrm{SO}_{4} \mathrm{Water}$ solution after 30 days of immersion.

15\%SA 3D printed objects using the 3D pen, FDM 3D printer and the growing robot revealed that each layer had an approximate diameter of 750, 370 and $1300 \mu \mathrm{m}$ respectively. The SEM and optical microscopy images are illustrated in Fig. S2 (ESI $\dagger$ ). Moreover, three different concentrations were tried for the FDM 3D printer; 5, 15 and $30 \%$ SA. The 3D objects using the Creality CR-10 model FDM printer are shown in Fig. S3 (ESI $\dagger$ ).

All the 3D-printed structures were able to adsorb $\mathrm{Cu}$ ions as observed from Fig. 7a-d. To better understand the $\mathrm{Cu}$ adsorption of the 3D structures and compare it with the one of the filaments shown before in Fig. 5, the 3D structures were cut into sizes that weighed $100 \mathrm{mg}$ and then immersed in $6 \mathrm{~mL}$ of $0.17 \% \mathrm{Cu}_{2} \mathrm{SO}_{4}$ water solution. The results are shown in Fig. $7 \mathrm{f}$ and a photo of the $3 \mathrm{D}$ structures is shown in Fig. 7e after 15 days of $\mathrm{Cu}$ adsorption. In detail the 3D pen, FDM 3D printed and growing robot PCL structures (without SA) found no $\mathrm{Cu}$ adsorption during their immersion in the $0.17 \% \mathrm{Cu}_{2} \mathrm{SO}_{4}$ water solution as observed from both Fig. 7e and f. From the other side, the 3D pen, FDM 3D printed and growing robot PCL/ $15 \%$ SA structures were able to adsorb $\mathrm{Cu}$ ions as shown in Fig. 7d and e. Most of the $\mathrm{Cu}$ adsorption from the 3D PCL/ 15\%SA structures happened during the first 3 days of their immersion in the $0.17 \% \mathrm{Cu}_{2} \mathrm{SO}_{4}$ water solution. Within 3 days of their immersion in the $\mathrm{Cu}$ solution, the 3D pen, the FDM 3D printed and the 3D growing robot structures were able to adsorb $20.1 \%, 14.4 \%$ and $15.4 \%$ of $\mathrm{Cu}$ ions respectively. Within 30 days of their immersion in the $0.17 \% \mathrm{Cu}_{2} \mathrm{SO}_{4}$ water solution the adsorption of the $\mathrm{Cu}$ ions was $23.6 \%, 22.8 \%$ and $21.9 \%$ for the 3D pen, FDM 3D and 3D growing robot structures respectively. The reason that the growing robot 3D structure adsorbed slightly less $\mathrm{Cu}$ ions compared to the 3D pen and FDM structures was that it has a lower surface to volume ratio due to the design and to the different extruded diameters obtained by the 3D pen, FDM and by the growing robot, whose resulting filament diameter was approximately $0.75,0.37$ and $1.3 \mathrm{~mm}$, respectively, but also due to the higher surface to volume ratio of the 3D pen structure, which was less layered compared to the FDM and growing robot structures.

The above results demonstrated that PCL/SA filaments up to $15 \%$ SA were stable in water whereas at higher SA concentration some SA loss was detected. From the other side, when the PCL/ SA filaments or 3D structures were immersed in 0.17 or $1 \% \mathrm{w} / \mathrm{w}$ $\mathrm{Cu}_{2} \mathrm{SO}_{4}$ water solution, there was no SA loss detected. This is due to the fact that $\mathrm{Cu}$ ions are crosslinked to sodium alginate as a crosslinking agent such as $\mathrm{CaCl}_{2}$ does. Previous research has shown that the gelation or crosslinking is high when the salt $\left(\mathrm{CaCl}_{2}\right)$ concentration is $1.4 \%$ and decreases at higher or lower values. ${ }^{32}$

The above results indicated that PCL/SA filaments and 3D printed structures were able to adsorb $\mathrm{Cu}$ ions on their surface. This mainly happened by replacing Na ions found in the PCL/ SA composite with $\mathrm{Cu}$ ions. The molecular scheme of capturing $\mathrm{Cu}$ ions that replaced $\mathrm{Na}$ ions of $\mathrm{SA}$ is illustrated in Fig. 8. Copper ions $\left(\mathrm{Cu}^{2+}\right)$ are able to replace $\mathrm{Na}$ ions, since the former can create bidentate bonds between two carboxylate groups of the alginate chains and therefore form stronger bonds than the 

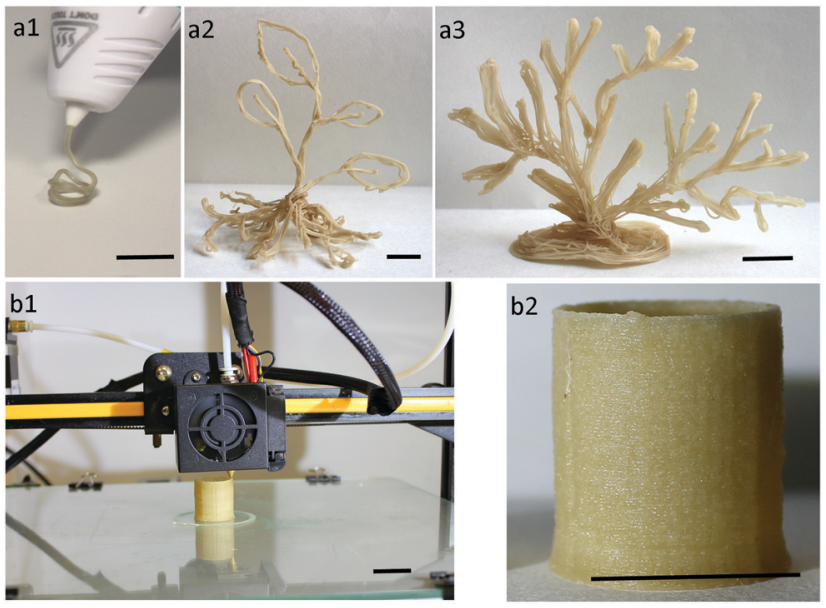

c1

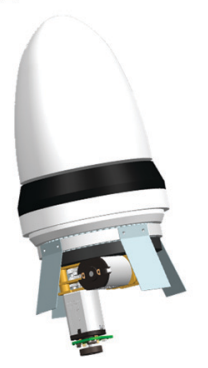

c2

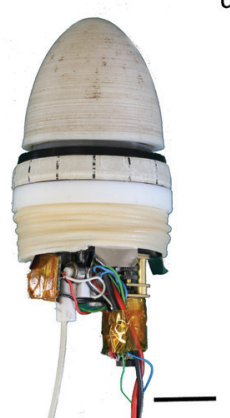

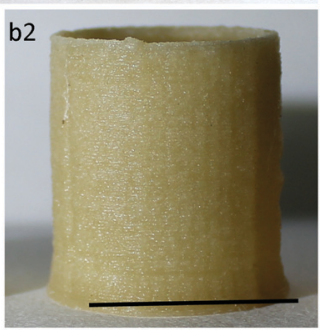

c3

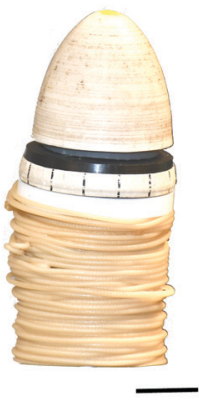

Fig. 6 (a1) 3D pen with PCL/15\%SA; (a2) and (a3) 3D pen plant-like and macroalgae-like structures with $\mathrm{PCL} / 15 \% \mathrm{SA}$; (b1) and (b2) 3D printed $\mathrm{PCL} /$ $15 \% \mathrm{SA}$; (c1) CAD model of the growing robot; and (c2) and (c3) PCL/15\%SA deposition in the growing robot. Scale bars $=2 \mathrm{~cm}$.

mono-dentate COO-Na bond. The mechanism of heavy metal accumulation on these artificial PCL/SA composites is very similar to the ion exchange mechanism and to chelation present in macroalgae and plant species respectively. ${ }^{26,28}$ Therefore, the artificial PCL/SA 3D structures were acting biomimetically by accumulating heavy metals (copper) as other marine or terrestrial plant species can do.

The obtained results revealed that a PCL/5\%SA filament weighing $100 \mathrm{mg}$ was able to adsorb $11.3 \%$ of the amount of $\mathrm{Cu}$ ions in the $0.17 \% \mathrm{w} / \mathrm{w} \mathrm{Cu}_{2} \mathrm{SO}_{4} 6 \mathrm{~mL}$ vial (Fig. 5a) containing $10.2 \mathrm{mg}$ of $\mathrm{Cu}_{2} \mathrm{SO}_{4}$ within 3 days. Consequently the adsorption capacity of this filament at 3 days was $11.5 \mathrm{mg} \mathrm{g}^{-1}$. The equation used to obtain the adsorption capacity in $\mathrm{mg} \mathrm{g}^{-1}$ for the PCL $/ 5 \%$ SA filament in $0.17 \%$ concentration $\mathrm{w} / \mathrm{w} \mathrm{Cu}_{2} \mathrm{SO}_{4}$ was: $1000 \mathrm{mg} \times((11.3 / 100) \times 10.2 \mathrm{mg}) / 100 \mathrm{mg}=11.5 \mathrm{mg}$. Similarly, the obtained results revealed that a PCL/15\%SA filament weighing $100 \mathrm{mg}$ was able to completely adsorb $17 \%$ of the amount of $\mathrm{Cu}$ ions in the $0.17 \% \mathrm{w} / \mathrm{w} \mathrm{Cu}_{2} \mathrm{SO}_{4} 6 \mathrm{~mL}$ vial (Fig. 5b) containing $10.2 \mathrm{mg}$ of $\mathrm{Cu}_{2} \mathrm{SO}_{4}$ within 3 days. Consequently the adsorption capacity of this filament at 3 days was $17.3 \mathrm{mg} \mathrm{g}^{-1}$. Furthermore, the obtained results revealed that a $\mathrm{PCL} / 30 \%$ SA filament weighing $100 \mathrm{mg}$ was able to adsorb $38.4 \%$ of the amount of $\mathrm{Cu}$ ions in the $0.17 \% \mathrm{w} / \mathrm{w} \mathrm{Cu}_{2} \mathrm{SO}_{4}$ $6 \mathrm{~mL}$ vial (Fig. $5 \mathrm{c}$ ) containing $10.2 \mathrm{mg}$ of $\mathrm{Cu}_{2} \mathrm{SO}_{4}$ within 3 days. Consequently the adsorption capacity of this filament was
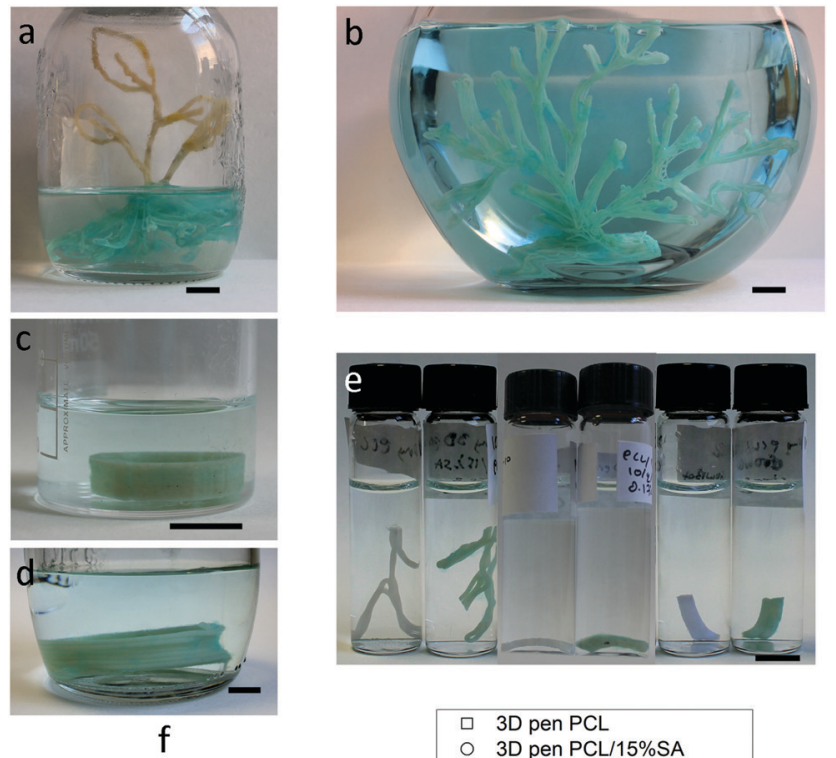

$\mathrm{f}$

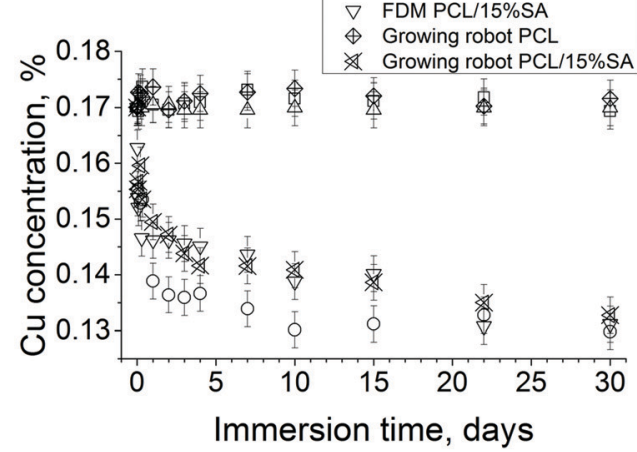

Fig. 7 Photographs of 3D printed structures immersed in $0.17 \% \mathrm{w} / \mathrm{w}$ $\mathrm{Cu}_{2} \mathrm{SO}_{4}$ water solution after 2 weeks (a) 3D plant, (b) 3D macroalgae and (c) FDM 3D printed and (d) 3D growing robot structures; (e) photographs of 3D pen PCL, 3D pen PCL/15\%SA, FDM 3D PCL, FDM 3D PCL/15\%SA, growing robot $P C L$ and growing robot $P C L / 15 \% S A$ structures (from left to right) and ( $f$ ) kinetics of the $\mathrm{Cu} \%$ concentration of the 3D printed structures in $0.17 \% \mathrm{w} / \mathrm{w} \mathrm{Cu}_{2} \mathrm{SO}_{4}$ water solution. Scale bars $=1 \mathrm{~cm}$.

$39.2 \mathrm{mg} \mathrm{g}^{-1}$. Similarly, a PCL/5\%SA filament weighing $100.0 \mathrm{mg}$ was able to adsorb approximately $2.2 \%(2.227 \%)$ of the amount of $\mathrm{Cu}$ ions within 3 days in the $1 \% \mathrm{w} / \mathrm{w} \mathrm{Cu} \mathrm{Cu}_{2} \mathrm{SO}_{4}$ solution $6 \mathrm{~mL}$ vial (Fig. 5b) containing $60 \mathrm{mg}$ of $\mathrm{Cu}_{2} \mathrm{SO}_{4}$. Therefore the maximum adsorption capacity of the PCL/5\%SA filament in $1 \% \mathrm{w} / \mathrm{w} \mathrm{Cu}_{2} \mathrm{SO}_{4}$ solution was approximately $13.4 \mathrm{mg} \mathrm{g}^{-1}$ for 3 days of immersion. The equation used to obtain the adsorption capacity in $\mathrm{mg} \mathrm{g}^{-1}$ for the PCL/5\%SA filament in $1 \% \mathrm{w} / \mathrm{w} \mathrm{Cu}_{2} \mathrm{SO}_{4}$ concentration was: $1000 \mathrm{mg} \times((2.227 / 100) \times 60 \mathrm{mg}) / 100 \mathrm{mg}=13.4 \mathrm{mg}$. A PCL/15\%SA filament weighing $100 \mathrm{mg}$ was able to adsorb approximately $3.0 \%$ of the amount of $\mathrm{Cu}$ ions within 3 days in the $1 \% \mathrm{w} / \mathrm{w} \mathrm{Cu}_{2} \mathrm{SO}_{4}$ solution $6 \mathrm{~mL}$ vial (Fig. $5 \mathrm{~b}$ ) containing $60 \mathrm{mg}$ of $\mathrm{Cu}_{2} \mathrm{SO}_{4}$. Therefore the maximum adsorption capacity of the $\mathrm{PCL} / 15 \% \mathrm{SA}$ filament in $1 \% \mathrm{w} / \mathrm{w} \mathrm{Cu}_{2} \mathrm{SO}_{4}$ solution was approximately $17.9 \mathrm{mg} \mathrm{g}^{-1}$ for 3 days of immersion. Similarly, a PCL/30\%SA filament weighing $100 \mathrm{mg}$ was able to adsorb approximately $3.9 \%$ of the amount of $\mathrm{Cu}$ ions within 3 days in the $1 \% \mathrm{w} / \mathrm{w} \mathrm{Cu}_{2} \mathrm{SO}_{4}$ solution $6 \mathrm{~mL}$ vial (Fig. $5 \mathrm{~d}$ ) containing $60 \mathrm{mg}$ of $\mathrm{Cu}_{2} \mathrm{SO}_{4}$. Therefore the maximum adsorption 


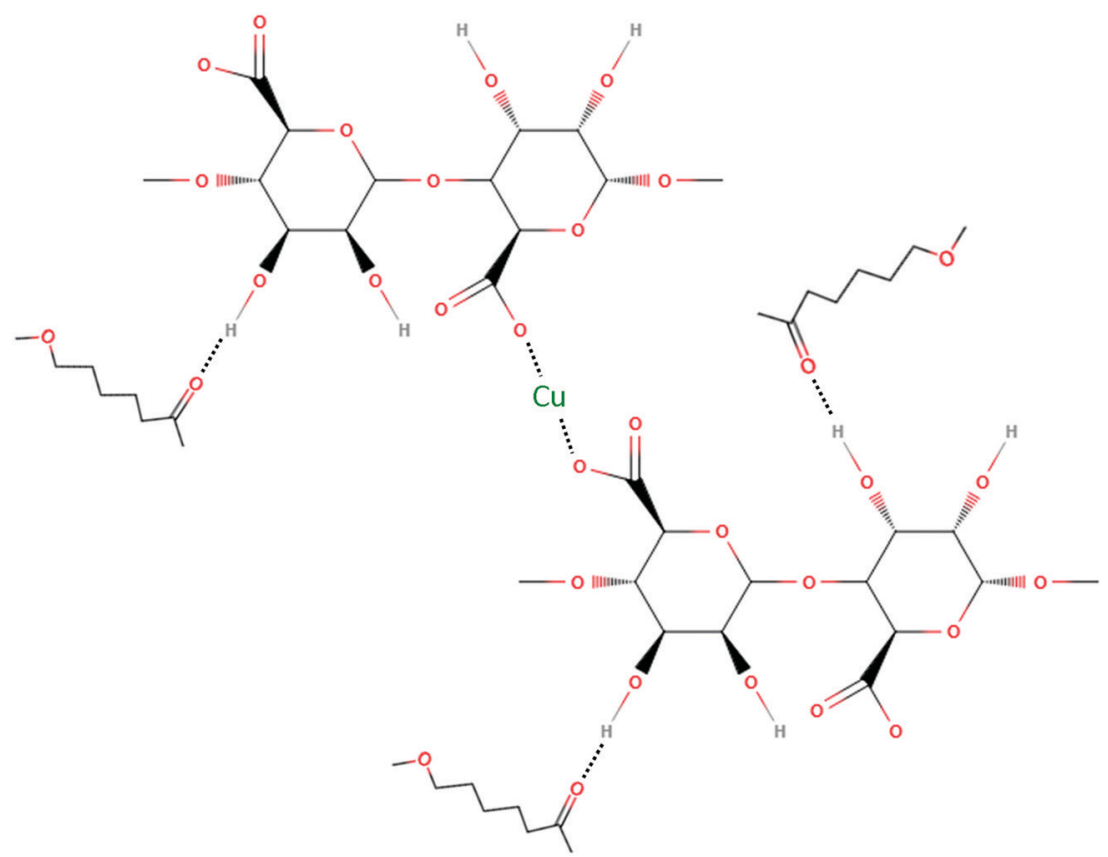

Fig. 8 Proposed molecular mechanism of $\mathrm{Cu}$ ion adsorption on PCL/SA composites.

capacity of the PCL/30\%SA filament in $1 \% \mathrm{w} / \mathrm{w} \mathrm{Cu}_{2} \mathrm{SO}_{4}$ solution was approximately $23.2 \mathrm{mg} \mathrm{g}^{-1}$ for 3 days of immersion.

The first trials using a 3D printing pen, an FDM 3D printer and a growing robot shown in Fig. 6 and 7 illustrated that the PCL/15\%SA filament was 3D printed and the printed objects, such as plant-like, macroalgae-like and tubular root or shootlike structures, were able to adsorb copper ions as the freestanding filament did. The 3D pen structure was able to adsorb slightly more copper than the tubular structures due to the higher surface area to volume ratio exposed in the copper solution of the 3D pen structure. The maximum adsorption capacities of both the filaments and 3D structures for SA concentrations 5, 15 and $30 \%$ and for the studied immersion times are summarised in Table 1 . Another important result that can be extracted from Table 1 is that the PCL/SA filaments and consequently $3 \mathrm{D}$ structures were able to adsorb more $\mathrm{Cu}$ ions in the higher concentration of $\mathrm{Cu}_{2} \mathrm{SO}_{4}(1 \%)$ compared to the lower one $(0.17 \%)$, especially for the PCL/5-15\%SA concentration. For the $\mathrm{PCL} / 30 \% \mathrm{SA}$ filaments the adsorption capacity in the $1 \%$ $\mathrm{Cu}_{2} \mathrm{SO}_{4}$ concentration will be higher at longer times. Other researchers have also shown that the $\mathrm{Cu}$ and $\mathrm{Pb}$ adsorption on MXene/alginate composites is increased by increasing the $\mathrm{Cu}$ and $\mathrm{Pb}$ concentration in the solution up to a point and then reaches a plateau, due to the lack of active sites to adsorb more heavy metals. ${ }^{36}$ Similar results have also been obtained by using a calcium alginate/graphene oxide composite aerogel for removing $\mathrm{Pb}, \mathrm{Cu}$ and $\mathrm{Cd}$ ions. ${ }^{10}$

The maximum adsorption capacity of the PCL/30\%SA filament $\left(93.3 \mathrm{mg} \mathrm{g}^{-1}\right.$ or $87.9 \mathrm{mg} \mathrm{g}^{-1}$ for the $0.17 \%$ or $1 \% \mathrm{w} / \mathrm{w}$ $\mathrm{Cu}_{2} \mathrm{SO}_{4}$ solution respectively) but also of the $3 \mathrm{D}$ printed structures made of $\mathrm{PCL} / 15 \% \mathrm{SA}\left(22-24 \mathrm{mg} \mathrm{g}^{-1}\right.$ for the $0.17 \% \mathrm{w} / \mathrm{w}$ $\mathrm{Cu}_{2} \mathrm{SO}_{4}$ solution) is comparable with other composites and materials that are able to adsorb $\mathrm{Cu}$ ions such as a graphene oxide/cellulose hydrogel $\left(47.5-88.5 \mathrm{mg} \mathrm{g}^{-1}\right),{ }^{37}$ polydopamine coated natural zeolites $\left(28.58 \mathrm{mg} \mathrm{g}^{-1}\right),{ }^{38}$ calcium alginate beads (42.7 $\mathrm{mg} \mathrm{g}^{-1}$ ) and calcium alginate/graphene oxide beads $\left(60.2 \mathrm{mg} \mathrm{g}^{-1}\right),{ }^{39}$ modified polyacrylonitrile with a diazoresinethylenediaminetetraacetic acid (DR-EDTA) layer $\left(47.6 \mathrm{mg} \mathrm{g}^{-1}\right),{ }^{40}$ granular activated carbon supported titanium dioxide particles $\left(23.42 \mathrm{mg} \mathrm{g}^{-1}\right),{ }^{41}$ hydroxyapatite nanoparticles $\left(70.92 \mathrm{mg} \mathrm{g}^{-1}\right),{ }^{42}$ spent coffee powder coated with polyethylenimine and ferric ions (200.1 $\left.\mathrm{mg} \mathrm{g}^{-1}\right){ }^{43}$ triethylenetetramine and tetraethylenepentamine covalently immobilized onto macroporous poly(glycidyl methacrylate-co-trimethylolpropane trimethacrylate) microspheres (64.44 and $\left.58.48 \mathrm{mg} \mathrm{g}^{-1}\right)^{44}$ and wood biochar in the absence and presence of humic or fulvic acid (19-30 $\left.\mathrm{mg} \mathrm{g}^{-1}\right) .{ }^{45}$ Recently, wheat straw cellulose based hydrogels with semi-interpenetrating network polymers of SA or poly(vinyl alcohol) showed copper ion adsorption capacities (22.5 or $20.0 \mathrm{mg} \mathrm{g}^{-1}$ respectively) ${ }^{16}$ within a few hours. The time of the maximum adsorption between different materials is difficult to compare since the adsorption time is related to the initial concentration of the copper ion solution, type of material, such as nanoparticles or composites, etc. To give an estimation, triethylenetetramine and tetraethylenepentamine covalently immobilized onto macroporous poly(glycidyl methacrylate-cotrimethylolpropane trimethacrylate) microspheres reached maximum adsorption in a few minutes when the $\mathrm{Cu}$ ion concentration was around $10 \mathrm{mM}{ }^{44}$ Laterite treated with $\mathrm{HCl}$ reached its maximum adsorption capacity within $120 \mathrm{~min}$ in a $100 \mathrm{mg} \mathrm{L}{ }^{-1}$ initial copper ion concentration. ${ }^{46}$ Alginate beads needed about 90 min to reach the maximum $\mathrm{Cu}$ ion adsorption capacity. ${ }^{39}$ In the case of the PCL/30\%SA filament presented here, the time to reach the maximum $\mathrm{Cu}$ ion adsorption capacity was much more ( $>30$ days), but this filament reached 


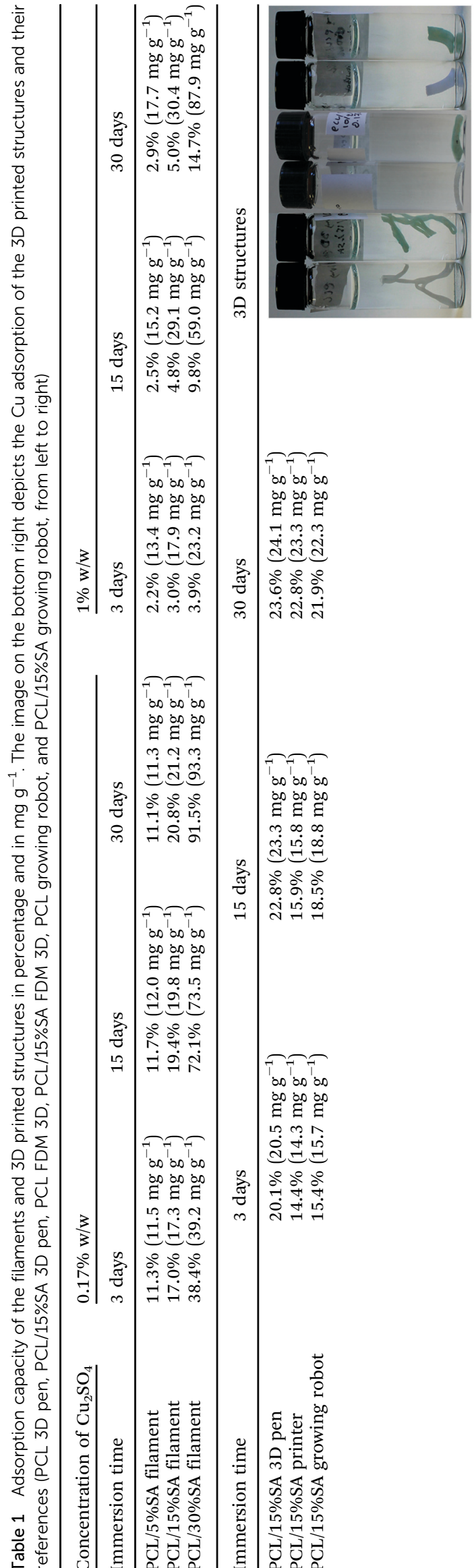

a comparatively high value of the maximum adsorption capacity and the concentrations used to study the adsorption of $\mathrm{Cu}$ ions were also comparatively high ( 0.17 and $1 \% \mathrm{w} / \mathrm{w})$. PCL/SA filaments or 3D printed structures take more time to adsorb copper ions compared to calcium alginate beads, since calcium alginate beads in contact with water can swell within a few hours and therefore adsorb high amounts of water and copper ions. This was also true for the PCL/SA films created prior to the extrusion process. Sodium alginate in PCL/SA films was loosely bonded and not uniformly mixed as also observed from the melting points and \% crystallinity of PCL/SA films, which did not show any trend (Fig. S4 in the ESI $\dagger$ ) as the filaments showed (Fig. 3e). Additionally, as can be seen in Fig. S5b (ESI $\dagger$ ), the PCL/30\%SA films reached the maximum adsorption capacity within 1 day when immersed into a $1 \% \mathrm{w} / \mathrm{w} \mathrm{Cu}_{2} \mathrm{SO}_{4}$ solution (note that for the $0.17 \% \mathrm{w} / \mathrm{w} \mathrm{Cu}_{2} \mathrm{SO}_{4}$ solution the analysis was stopped since SA detached from the PCL film (Fig. S5a, ESI $\dagger$ )), since SA was only found on the top of one side of the PCL film and therefore not mixed inside the PCL. From the other side, PCL/SA filaments do not swell significantly; SA was mixed also homogeneously inside the PCL and therefore their adsorption time is slower. The main advantages of PCL/SA filaments compared to other composites or polymers towards heavy metal adsorption are that they are homogeneous and have comparably high adsorption capacity and more importantly such filaments have high mechanical strength and can be used in 3D printing technology to create software-designed 3D composites. The 3D printed composites made from PCL/15\%SA structures (from the 3D pen and growing robot) were able to adsorb between 15 and $20 \%$ of the $\mathrm{Cu}$ ions within the first 3 days when immersed in the $0.17 \% \mathrm{w} / \mathrm{w} \mathrm{Cu}_{2} \mathrm{SO}_{4}$ solution. The presented results (Fig. 5 and 7 and Table 1) showed that the maximum adsorption is reached faster when the SA concentration in the PCL polymer was 5 or $15 \%$ rather than the $30 \%$ SA concentration composites. The time needed for the full adsorption capacity for the 5 and 15\% SA composites is about 3 days, whereas the one of the $30 \%$ SA was more than 30 days.

In this work a solvent was used to mix PCL and SA; from the resulting films, filaments were produced. A preliminary study showed that it is possible to obtain such PCL/SA filaments by mixing directly PCL and SA in the heat extruder and therefore avoid the solvent use. An example is shown in Fig. S6 (ESI†). Such filaments (without the use of the solvent) were found to have similar $\mathrm{Cu}$ adsorption properties to the ones created using DCM solvent. Also they were able to create 3D-printed structures as shown in Fig. S7a and b (ESI $\dagger$ ). The Cu adsorption of the 3D-printed structures (made from filaments without the use of DCM solvent) is shown in Fig. S7c (ESI $\dagger$ ) and was comparable with the one of the 3D-printed structure made from a filament which has been created from the PCL/SA film with the use of DCM solvent as described in the experimental section. Notwithstanding, the solvent method was preferred since it produced more homogeneous filaments, thanks to a more homogeneous starting composite (cut films) obtained before entering the extruder. Another method that we will explore in the future is to use micro-compounding to mix PCL and SA using heat and mechanical mixing to create homogeneous PCL/SA pellets. 


\section{Conclusions}

Innovative composite thermoplastic filaments of PCL with SA polysaccharide were created using dissolution, film formation and heat extrusion methods. The composite PCL/SA filaments were stable in deionised water without any leak of SA from the PCL thermoplastic matrix until the 15\% SA concentration, whereas at higher SA concentrations (20-30\%) a little loss of SA was detected. Nevertheless, such filaments or 3D printed composites independently of their SA concentration $(5-30 \% \mathrm{w} / \mathrm{w})$ were very stable in heavy metal contaminated deionised water and in air, which makes them very useful either in contaminated aquatic or atmospheric robotic applications. We proposed that the interaction and stability of SA with PCL were due to the formation of hydrogen bonds between the hydroxyl groups of the former and the carbonyl groups of the latter. SA kept its heavy metal adsorption properties within the PCL filament and was able to remove $91.5 \%$ of copper ions from a $0.17 \% \mathrm{w} / \mathrm{w}$ copper sulphate water solution, within 30 days (PCL/30\% filament). The maximum adsorption capacity of the PCL/30\%SA filament in a $0.17 \% \mathrm{w} / \mathrm{w}$ copper sulphate water solution was $93.3 \mathrm{mg} \mathrm{g}^{-1}$ for 30 days of immersion. Importantly, the PCL/SA filaments were inserted into a 3D pen, an FDM 3D printer and a growing robot and 3D plantbiomimetic structures were formed. The biomimetic 3D structures were able to adsorb copper from a $0.17 \% \mathrm{w} / \mathrm{w}$ copper sulphate water solution. A weight of $100 \mathrm{mg}$ of the PCL/15\%SA 3D printed structures in $6 \mathrm{~mL}$ of $0.17 \% \mathrm{w} / \mathrm{w} \mathrm{Cu}_{2} \mathrm{SO}_{4}$ solution was able to adsorb $22.3,23.3$ and $24.1 \mathrm{mg} \mathrm{g}^{-1}$ within 30 days, for the growing robot, the FDM 3D printer and the 3D pen structures respectively. The amount of SA in PCL was found to be correlated with the copper ion adsorption capacity: the higher the SA percentage, the higher the adsorption. The PCL/SA composite filaments were effective in adsorbing $\mathrm{Cu}$ ions in both lower and higher $\mathrm{Cu}_{2} \mathrm{SO}_{4}$ concentrations. In the future, such PCL/SA filaments and their 3D structures will be tested in more heavy metals and in different environments such as heavy metal contaminated moist air and additives such as inorganic particles will be inserted for targeting specific heavy metals. This work can pave the way towards new routes for water, air or soil remediation of heavy metals since the thermoplastic composite filaments have very good mechanical properties, are versatile and soft and can be used in additive manufacture technology.

\section{Abbreviations}

SA Sodium alginate

PCL Polycaprolactone

DCM Dichloromethane

FDM Fused deposition modelling

\section{Conflicts of interest}

The authors declare no conflicts of interest.

\section{Acknowledgements}

This study has received funding from the European Union's Horizon 2020 Research and Innovation Programme under Grant Agreement No. 824074 (GrowBot). I. L. L. wishes to acknowledge PhD candidate Ebrahim Shahabishalghouni for his assistance with Solidworks and Cura software for the design of the FDM 3D printed object.

\section{References}

1 P. B. Tchounwou, C. G. Yedjou, A. K. Patlolla and D. J. Sutton, Heavy metal toxicity and the environment, Exper. Suppl., 2012, 101, 133-164.

2 A. Aksu, Sources of metal pollution in the urban atmosphere (A case study: Tuzla, Istabul), J. Environ. Health Sci. Eng., 2015, 13, 79.

3 Health risks of heavy metals from long-range transboundary air pollution, World Health Organization, 2007, http://www. euro.who.int/en/publications/abstracts/health-risks-of-heavymetals-from-long-range-transboundary-air-pollution-2007.

4 Lead in Drinking-water World Health Organization, 2011, https://www.who.int/water_sanitation_health/dwq/chemi cals/lead.pdf.

5 Guidelines for Drinking-water Quality, World Health Organization, 2011, https:/www.who.int/water_sanitation_health/ publications/2011/dwq_guidelines/en/.

6 M. A. Barakat, New trends in removing heavy metals from industrial wastewater, Arabian J. Chem., 2011, 4, 361-377.

7 M. Jaishankar, T. Tseten, N. Anbalagan, B. B. Mathew and K. N. Beeregowda, Toxicity, mechanism and health effects of some heavy metals, Interdisciplinary, Toxicology, 2014, 7, 60-72.

8 S. Khalid, M. Shahid, N. K. Niazi, B. Murtaza, I. Bibi and C. Dumat, A comparison of technologies for remediation of heavy metal contaminated soils, J. Geochem. Explor., 2017, 182, 247-268.

9 L. Liu, W. Li, W. Song and M. Guo, Remediation techniques for heavy metal-contaminated soils: Principles and applicability, Sci. Total Environ, 2018, 633, 206-219.

10 L. Pan, Z. Wang, Q. Yang and R. Huang, Efficient Removal of Lead, Copper and Cadmium Ions from Water by a Porous Calcium Alginate/Graphene Oxide Composite Aerogel, Nanomaterials, 2018, 8, 957.

11 F. R. Sulaiman and H. A. Hamzah, Heavy metals accumulation in suburban roadside plants of a tropical area (Jengka, Malaysia), Ecolo. Processes, 2018, 7, 28.

12 V. S. Barcan, E. F. Kovnatsky and M. S. Smetannikova, Absorption of Heavy Metals in Wild Berries and Edible Mushrooms in an Area Affected by Smelter Emissions, Water, Air, Soil Pollut., 1998, 103, 173-195.

13 Q. Chen, X.-D. Pan, B.-F. Huang and J.-L. Han, Distribution of metals and metalloids in dried seaweeds and health risk to population in southeastern China, Sci. Rep., 2018, 8, 3578.

14 T. A. Jarvis and G. K. Bielmyer-Fraser, Accumulation and effects of metal mixtures in two seaweed species, Comp. Biochem. Physiol., Part C: Toxicol. Pharmacol., 2015, 171, 28-33. 
15 Z.-F. Yang, L.-Y. Li, C.-T. Hsieh, R.-S. Juang and Y. A. Gandomi, Fabrication of magnetic iron Oxide@Graphene composites for adsorption of copper ions from aqueous solutions, Mater. Chem. Phys., 2018, 219, 30-39.

16 W. Kong, Q. Li, X. Li, Y. Su, Q. Yue, W. Zhou and B. Gao, Removal of copper ions from aqueous solutions by adsorption onto wheat straw cellulose-based polymeric composites, J. Appl. Polym. Sci., 2018, 135, 46680.

17 W. Peng, H. Li, Y. Liu and S. Song, A review on heavy metal ions adsorption from water by graphene oxide and its composites, J. Mol. Liq., 2017, 230, 496-504.

18 M. Karnib, A. Kabbani, H. Holail and Z. Olama, Heavy Metals Removal Using Activated Carbon, Silica and Silica Activated Carbon Composite, Energy Procedia, 2014, 50, 113-120.

19 C. Ren, X. Ding, W. Li, H. Wu and H. Yang, Highly Efficient Adsorption of Heavy Metals onto Novel Magnetic Porous Composites Modified with Amino Groups, J. Chem. Eng. Data, 2017, 62, 1865-1875.

20 M. Kragović, S. Pašalić, M. Marković, M. Petrović, B. Nedeljković, M. Momčilović and M. Stojmenović, Natural and Modified Zeolite-Alginate Composites. Application for Removal of Heavy Metal Cations from Contaminated Water Solutions, Minerals, 2018, 8, 11.

21 X. Yang, T. Zhou, B. Ren, A. Hursthouse and Y. Zhang, Removal of $\mathrm{Mn}$ (II) by Sodium Alginate/Graphene Oxide Composite Double-Network Hydrogel Beads from Aqueous Solutions, Sci. Rep., 2018, 8, 10717.

22 C.-X. Cai, J. Xu, N.-F. Deng, X.-W. Dong, H. Tang, Y. Liang, X.-W. Fan and Y.-Z. Li, A novel approach of utilization of the fungal conidia biomass to remove heavy metals from the aqueous solution through immobilization, Sci. Rep., 2016, 6, 36546.

23 M. Wang, Z. Wang, X. Zhou and S. Li, Efficient Removal of Heavy Metal Ions in Wastewater by Using a Novel AlginateEDTA Hybrid Aerogel, Appl. Sci., 2019, 9, 547.

24 N. Yang, R. Wang, P. Rao, L. Yan, W. Zhang, J. Wang and F. Chai, The Fabrication of Calcium Alginate Beads as a Green Sorbent for Selective Recovery of $\mathrm{Cu}$ (II) from Metal Mixtures, Crystals, 2019, 9, 255.

25 A. Sadeghi, A. Mondini and B. Mazzolai, Toward Self-Growing Soft Robots Inspired by Plant Roots and Based on Additive Manufacturing Technologies, Soft Robot., 2017, 4, 211-223.

26 M. Bilal, T. Rasheed, J. E. Sosa-Hernández, A. Raza, F. Nabeel and H. M. N. Iqbal, Biosorption: An Interplay between Marine Algae and Potentially Toxic Elements-A Review, Mar. Drugs, 2018, 16, 65.

27 O. Raize, Y. Argaman and S. Yannai, Mechanisms of biosorption of different heavy metals by brown marine macroalgae, Biotechnol. Bioeng., 2004, 87, 451-458.

28 K. Viehweger, How plants cope with heavy metals, Bot. Stud., 2014, 55, 35.

29 F. P. de Araujo, I. T. Silva Batista, F. C. de Oliveira, L. R. de Almeida, G. de Castro Brito, H. da Silva Barud, D. Dittz, E. C. Silva-Filho, J. A. Osajima and A. O. Lobo, Printing composite nanofilaments for use in a simple and low-cost 3D pen, J. Mater. Res., 2020, 35, 1154-1162.
$30 \mathrm{H}$. Tetsuka and S. R. Shin, Materials and technical innovations in 3D printing in biomedical applications, J. Mater. Chem. B, 2020, 8, 2930-2950.

31 I. L. Liakos, A. Mondini, C. Filippeschi, V. Mattoli, F. Tramacere and B. Mazzolai, Towards ultra-responsive biodegradable polysaccharide humidity sensors, Mater. Today Chem., 2017, 6, 1-12.

32 T. R. Cuadros, O. Skurtys and J. M. Aguilera, Mechanical properties of calcium alginate fibers produced with a microfluidic device, Carbohydr. Polym., 2012, 89, 1198-1206.

33 E. G. Kim, B. S. Kim and D. S. Kim, Physical properties and morphology of polycaprolactone/starch/pine-leaf composites, J. Appl. Polym. Sci., 2007, 103, 928-934.

34 L. Zhu, J. Qiu and E. Sakai, A high modulus hydrogel obtained from hydrogen bond reconstruction and its application in vibration damper, $R S C A d v$., 2017, 7, 43755-43763.

35 M. Guo, L. M. Pitet, H. M. Wyss, M. Vos, P. Y. W. Dankers and E. W. Meijer, Tough Stimuli-Responsive Supramolecular Hydrogels with Hydrogen-Bonding Network Junctions, J. Am. Chem. Soc., 2014, 136, 6969-6977.

36 Y. Dong, D. Sang, C. He, X. Sheng and L. Lei, Mxene/alginate composites for lead and copper ion removal from aqueous solutions, RSC Adv., 2019, 9, 29015-29022.

37 X. Chen, S. Zhou, L. Zhang, T. You and F. Xu, Adsorption of Heavy Metals by Graphene Oxide/Cellulose Hydrogel Prepared from $\mathrm{NaOH} /$ Urea Aqueous Solution, Materials, 2016, 9, 582.

38 Y. Yu, J. G. Shapter, R. Popelka-Filcoff, J. W. Bennett and A. V. Ellis, Copper removal using bio-inspired polydopamine coated natural zeolites, J. Hazard. Mater., 2014, 273, 174-182.

39 W. M. Algothmi, N. M. Bandaru, Y. Yu, J. G. Shapter and A. V. Ellis, Alginate-graphene oxide hybrid gel beads: An efficient copper adsorbent material, J. Colloid Interface Sci., 2013, 397, 32-38.

40 X. Zhang, S. Yang, B. Yu, Q. Tan, X. Zhang and H. Cong, Advanced Modified Polyacrylonitrile Membrane with Enhanced Adsorption Property for Heavy Metal Ions, Sci. Rep., 2018, 8, 1260.

41 X. Zheng, N. Yu, X. Wang, Y. Wang, L. Wang, X. Li and $\mathrm{X}$. Hu, Adsorption Properties of Granular Activated CarbonSupported Titanium Dioxide Particles for Dyes and Copper Ions, Sci. Rep., 2018, 8, 6463.

42 P. Joshi and S. Manocha, Kinetic and thermodynamic studies of the adsorption of copper ions on hydroxyapatite nanoparticles, Mater. Today: Proc., 2017, 4, 10455-10459.

43 L. Hao, P. Wang and S. Valiyaveettil, Successive extraction of $\mathrm{As}(\mathrm{v}), \mathrm{Cu}(\mathrm{II})$ and $\mathrm{P}(\mathrm{v})$ ions from water using spent coffee powder as renewable bioadsorbents, Sci. Rep., 2017, 7, 42881.

44 Z. Yu, R. a. Wu, M. Wu, L. Zhao, R. Li and H. Zou, Preparation of polyamine-functionalized copper specific adsorbents for selective adsorption of copper, Colloids Surf., $B, 2010,78,222-228$.

45 P. He, Q. Yu, H. Zhang, L. Shao and F. Lü, Removal of Copper(II) by Biochar Mediated by Dissolved Organic Matter, Sci. Rep., 2017, 7, 7091.

46 K. Sudha Rani, B. Srinivas, K. GouruNaidu and K. V. Ramesh, Removal of copper by adsorption on treated laterite, Mater. Today: Proc., 2018, 5, 463-469. 